\title{
A integração de saberes por meio da temática das sementes crioulas na formação de professores de ciências para o
} campo

\author{
The integration of knowledge through traditional seeds theme in \\ training science teachers for rural education
}

\author{
Tânia Halley Oliveira Pinto1; Verônica Klepka²; Mikaella de Sousa ${ }^{3}$; Rodrigo dos \\ Santos Crepalde ${ }^{4}$
}

1 Doutoranda em Educação em Ciências, Professora na Universidade Federal do Triângulo Mineiro - UFTM, Uberaba, Minas Gerais, Brasil - taniahalley@ gmail.com/ORCID 0000-0002-1368-4451

2 Doutora em Educação para a Ciência e a Matemática, Professora na Universidade Federal do Triângulo Mineiro - UFTM, Uberaba, Minas Gerais, Brasil - veronicaklepka@gmail.com/ORCID 0000-0002-9937-9852

3 Mestra em Ensino de Ciências, Professora da Rede Estadual de Minas Gerais e da Escola SESI, Uberaba, Minas Gerais, Brasil - mikaelladesousa@ hotmail.com/ORCID 0000-0001-9092-8467

4 Doutor em Educação em Ciências, Professor na Universidade Federal do Triângulo Mineiro - UFTM, Uberaba, Minas Gerais, Brasil - rodrigocrepalde@gmail.com/ORCID 0000-0001-7025-7010

\section{Recebido em Agosto/2019. Publicado em Agosto/2020}

Palavras-chave:

Sementes Crioulas. Interculturalidade. Conhecimento

Tradicional. Ensino de Ciências. Educação do Campo.

\section{Keywords:}

Traditional seeds. Interculturality. Traditional Knowledge Science teaching. Rural Education.
RESUMO: As sementes são essenciais para a manutenção da diversidade biológica. No Brasil, a prática de seleção, guarda e plantio de sementes é um traço cultural identitário de muitas comunidades tradicionais do campo. Nestes contextos, as sementes crioulas, em suas múltiplas denominações, fazem parte de um amplo repertório de conhecimentos relacionados a tradicionais práticas sociais, perfazendo ainda um patrimônio genético e símbolo cultural de resistência. Na perspectiva da integração de conhecimentos tradicionais no Ensino de Ciências, este artigo analisa, a partir de pesquisa qualitativa sobre a própria prática docente, os pontos de articulação ou desarticulação da temática sementes crioulas aos conteúdos do Ensino de Ciências em um contexto de formação de professores para o campo. Discute-se a possibilidade de assumir, quando possível, aproximações e complementaridades entre os sistemas de conhecimento tradicional e científico no âmbito da temática sementes crioulas, e por outro lado reconhecer que há pontos de distanciamentos em que os sistemas de conhecimento caminharão em paralelo. Argumenta-se ainda que tais aproximações possibilitam o enriquecimento mútuo entre conhecimentos reduzindo a visão sobre os saberes tradicionais como algo exótico ou folclórico.

ABSTRACT: Seeds are essential for maintaining biological diversity. In Brazil, the practice of seed selection, storage and planting is a cultural identity trait of many traditional rural communities. In these contexts, the Traditional seeds, in their multiple denominations, are part of a broad repertoire of knowledge related to traditional social practices, making up a genetic heritage and cultural symbol of resistance. From the perspective of the integration of traditional knowledge in science teaching, this article analyzes from a qualitative research on the teaching practice itself, the points of articulation or disarticulation of the Traditional seeds theme to the contents of science education in a context of teacher education for rural education. It is discussed the possibility of assuming, when possible, approximations and complementarities between traditional and scientific knowledge systems in the 
context of the Traditional seeds theme, and on the other hand to recognize that there are points of distancing in which knowledge systems will go in parallel. It is further argued that such approaches enable mutual enrichment between knowledge by reducing the view of traditional knowledge as something exotic or folkloric.

\section{INTRODUÇÃO}

A manutenção e a ampliação da biodiversidade têm sido realizadas há muitos séculos pelos mais diversos povos ao redor do planeta. Suas práticas, principalmente de coleta e plantio de grãos, deram origem à agricultura e à domesticação de espécies antes exóticas, em agrícolas, resultando em novos e seguros recursos alimentícios. Juntos, plantas e seres humanos apresentam uma evolução conjunta na história da Terra e demarcam a forte relação entre a diversidade biológica e a diversidade cultural.

Para os camponeses, por exemplo, o manejo da biodiversidade está associado à vários fatores, entre eles às suas práticas alimentares e medicinais. O plantio está estreitamente relacionado também às condições locais, à adaptação de diversos cultivos e diferentes variedades de cada cultivo às condições climáticas, ambientais, sazonais, relevo, entre outros aspectos do lugar de que dispõem. Como resultado, a cada colheita homens e mulheres do campo "selecionam as sementes que melhor cumprem seus objetivos e voltam a plantá-las, sozinhas ou cruzando-as com outras" num constante exercício de experimentação e desenvolvimento de "cultivares locais adaptados a cada família, criando uma base de recursos para si próprios e [...] uma enorme diversidade" (RIBEIRO, 2003, p. 53). Assim, as sementes - enquanto patrimônio genético, símbolo cultural e prática social - correspondem a uma rica fonte de conhecimentos relacionados às comunidades tradicionais que os produzem.

As sementes, estacas ou mudas de plantas que não sofreram nenhum tipo de manipulação tecnológica para seu melhoramento, como a transgenia por exemplo, são frequentemente denominadas crioulas, dentre outros inúmeros nomes. Além de serem importantes para a manutenção da diversidade biológica, as sementes crioulas também exercem papel crucial no que tange a resistência de espécies nativas, saberes e comunidades tradicionais. Logo, a prática de seleção, guarda e plantio de sementes corresponde a um traço cultural identitário de muitas comunidades tradicionais. Como é o caso das populações do campo no Brasil.

São os saberes desses povos tradicionais que nos ensinam hoje a conservação da natureza, o uso em equilíbrio do ecossistema, o respeito aos ciclos e leis ambientais que, por outro lado, tornam-se resilientes, ou seja, tão diversos, que são capazes de se recuperarem às adversidades externas como ataques de insetos e/ou doenças. Em outras palavras, quanto mais diverso for o material genético dos cultivares, maior suas chances de sobrevivência. Nesse 
sentido, o saber e a prática dos povos tradicionais têm desempenhado importante papel na manutenção das espécies e na sua variabilidade genotípica e fenotípica.

A temática abordada das sementes crioulas surge da discussão sobre práticas sociais desenvolvidas por educandos do campo em suas comunidades e é apresentada neste trabalho como possibilidade de demarcação e cruzamento de fronteiras dos usos tradicional e científico de saberes, estimulando seu intercâmbio e enriquecimento mútuo em sala de aula. Para isso, assumimos a perspectiva da integração de conhecimentos tradicionais no Ensino de Ciências (AIKENHEAD; MICHELL, 2011; CREPALDE; KLEPKA; HALLEY; SOUSA, 2019).

Uma questão que surge com facilidade dessa discussão é: qual ou quais relações os conhecimentos tradicionais e científicos podem construir? Ou melhor, considerando que essas possíveis relações podem ser inumeráveis e inesgotáveis, pois são criadas ou transformadas por cada situação concreta, quais relações entre conhecimentos tradicionais e científicos emergem de um contexto em especial? E, quando pensamos em práticas pedagógicas, seria possível assumir ou incentivar uma posição enquanto educadores, no nosso caso, educadores ou formadores de professores para o campo?

O tema sementes crioulas constitui-se extremamente relevante para o Ensino de Ciências, e mais ainda para este contexto na formação de professores da Educação do Campo na medida em que permite uma abordagem interdisciplinar e possibilita compreender a lógica de resistência de populações tradicionais no processo de transformação da semente em mercadoria. Fomenta ainda não só identificar as potencialidades no cultivo das sementes crioulas como os fatores socioculturais envolvidos nessa prática social. Além disso, atua diretamente no resgate, valorização e integração desses saberes na sala de aula na medida em que dialoga não apenas com a tradição oral e as memórias coletivas de um grupo, mas também estimula a reflexão de que o uso consciente da terra é possível.

Entretanto, como reflexo da validade científica assumida pela sociedade moderna, tecnológica e industrial no qual estamos inseridos, algumas pesquisas têm utilizado do rigor científico apenas para fortalecer a qualidade genética das sementes crioulas sob o cuidado dos povos do campo (SILVA, et al., 2009a; SILVA, et al., 2009b; SILVA, 2011; SILVA et. al, 2017). A proposta de diálogo de saberes entre pesquisadores/pesquisadoras e agricultores/agricultoras do campo, defendida pelos trabalhos, tendem a valorizar o ponto de vista científico com o intuito de fundamentar os saberes tradicionais nos moldes da ciência ocidental.

O resgate e a conservação da agrobiodiversidade em apoio à luta e à resistência das comunidades do campo também são apresentados em estudos sobre sementes crioulas na convivência com o semiárido mineiro. Nessa direção, destacam a importância da criação de 
banco e/ou casa de sementes comunitárias como proposições da articulação em rede de guardiãs e guardiões de sementes locais/tradicionais conservadas por gerações (OLIVEIRA, 2014; BUSTAMANTE, ALVARENGA, LOPES, 2014; ALVARENGA, DAYRELL, 2016; PEREIRA et. al, 2016; REZENDE et. al., 2016).

Especificamente no que tange ao semiárido mineiro, foco de nossa pesquisa bibliográfica, não foi encontrado nenhum trabalho que apresentasse a abordagem das sementes crioulas relacionadas à Educação e/ou Ensino de Ciências. Entretanto, ao ampliar um pouco mais a pesquisa para outros contextos semiáridos, tais como o paraibano, tem-se a literatura em formato de cordel como ferramenta de ensino das sementes de paixão (SANTOS, DE ANDRADE, MEDEIROS, 2013). Já no semiárido sergipano, a criação de um espaço de formação e diálogo entre agricultores camponeses, guardiões e guardiãs de sementes crioulas, com o objetivo da troca de saberes do conhecimento tradicional no que diz respeito ao resgate e conservação das sementes (AMORIM et al., 2015).

Observamos no conjunto desse levantamento, a ausência de trabalhos que contribuam com diálogos de intercâmbio cultural entre o conhecimento tradicional e o científico. É com o intuito de suprir parte desta lacuna que nossos resultados de pesquisa são apresentados na sequência.

Em outros trabalhos temos defendido o ensino intercultural de ciências assim como o diálogo de saberes nos processos formativos de educadores do campo elencando algumas possibilidades dessa articulação (CREPALDE; KLEPKA; HALLEY, 2017). Argumentamos que há conhecimentos passíveis de serem reconhecidos e integrados no Ensino de Ciências destacando aqueles que do nosso contexto da formação de professores de ciências para o campo são emergentes devido sua estreita relação com as práticas sociais desenvolvidas por nossos educandos e/ou suas comunidades (CREPALDE; KLEPKA; HALLEY; SOUSA, 2019). Dentre esses temas, naquela ocasião já elencados, as sementes crioulas têm mostrado possibilidades concretas de integração, inclusive curricular, em disciplinas da área das ciências no contexto do Curso de Licenciatura em Educação do Campo da Universidade Federal do Triângulo Mineiro. Assim, este artigo resulta de pesquisas sobre a prática docente desenvolvidas em situações de ensino nas disciplinas de Genética, Evolução e Botânica, ao longo de dois anos na formação inicial de professores de ciências para o campo. Nosso objetivo é analisar, neste contexto, os pontos de articulação ou desarticulação da temática sementes crioulas aos conteúdos do Ensino de Ciências.

\section{SEMENTES CRIOULAS: SEMENTES QUE BROTAM IDENTIDADES TRADICIONAIS}


A palavra semente, denota vários sentidos. Por vezes, utilizada para denominar o sentido biológico de que é portadora, gênese da vida. Por outras tantas vezes, utilizada por quem recorre à metáfora de que com o tempo algo há de causar algum efeito, seja ele maléfico ou benéfico. No caso da discussão que aqui propomos, a palavra semente recebe um adjetivo que carrega ainda mais sentidos, o termo crioula agrega um quê de resistência a essas matriarcas da vida. São sementes que traduzem um modo de vivência e sobrevivência moldado na luta contra um sistema que expropria o direito do agricultor de relacionar-se livremente com a natureza à sua volta sem que seja pelo viés da lógica operante de mercantilização da vida. Mercantilizam a vida da planta, os saberes envolvidos na prática social do manejo da lavoura e com isso, mercantilizam o modo de viver dos homens e mulheres do campo.

O termo crioulo, apesar de possuir diversos usos, carrega comumente uma lógica de atribuição de misturas por trás de suas definições. Foi usado por muito tempo para referir-se a quem, embora descendente de europeus, nasceu nos países hispano-americanos e também em outros países que sofreram colonização europeia. Utilizado ainda para designar a ideia de mistura de raças, a exemplo da miscigenação entre negros nascidos no Brasil e descendentes europeus. Na linguística, se refere ao que resulta da mistura de uma língua nativa com outra estrangeira, geralmente a oficial dos países colonizadores. Há, nesse caso, sobretudo, uma conotação negativa ao termo, associada ao racismo e ao colonialismo, isto é, ser crioulo é um atributo daquele que não é um "genuíno" cidadão branco, ocidental, europeu, etc.

Do nosso ponto de vista, no caso do adjetivo na expressão sementes crioulas há um deslocamento do seu sentido colonial original. Além de indicar que tais sementes são adaptadas ao seu local de origem, segue uma lógica contrária à de designar miscigenações, busca intitular exatamente o oposto, que as sementes crioulas não são fruto de misturas ou miscigenações, tais sementes são fruto da resistência em misturá-las ou cruzá-las com plantas modificadas geneticamente.

São consideradas crioulas, as sementes, estacas ou mudas de plantas que não sofreram nenhum tipo de intervenção tecnológica laboratorial/industrial para seu melhoramento, como a transgenia, por exemplo. Assim, as sementes crioulas carregam em si alta biodiversidade e são identificadas como um "recurso regenerativo e de multiplicidade genética, fruto da diversidade cultural e de uma relação muito estreita e dinâmica desenvolvida por diversas comunidades com o meio ambiente e o espaço em que vivem" (BENTHIEN, 2010, p. 32). Por isso, além de serem importantes para a manutenção da diversidade biológica, as sementes crioulas também exercem papel crucial no que diz respeito à resistência de espécies nativas, saberes e comunidades tradicionais. 
Por possuir estreita relação com seu local de origem e com os saberes tradicionais é que essas sementes também são designadas por uma variedade de outros termos, de acordo com a localidade em que são tratadas, podendo ser conhecidas como: sementes da paixão (Paraíba); variedades crioulas (Paraná) (TRINDADE, 2006); sementes das famílias (Norte de Minas Gerais) e sementes Pretas (Triângulo Mineiro), por exemplo.

Acredita-se que a diversidade de nomenclaturas populares a essas sementes tenha ocorrido a partir da década de 1970, época em que ocorreu com grande intensidade a devastação de matas nativas e sua substituição por monoculturas de soja, milho, cana, eucalipto, entre outras culturas no Cerrado brasileiro (CARVALHO, 2012; PORTOGONÇALVES, 2014). Consequentemente, novos hábitos de plantio e cultivo assalariado foram sendo instalados no campo e isso contribuiu para que a tradição de colheita, armazenamento e plantio de sementes em sua própria terra pelo agricultor tradicional fosse alterada. Inicia-se a venda de sementes e com ela os mecanismos industriais de controle de parasitas e insetos por meio de insumos químicos, a exemplo dos grandes modelos de produção instalados. Tais modelos surgem e tem como marca a substituição do cuidado com o meio ambiente e com o próximo pela preocupação com o lucro potencial que a lavoura pode gerar. Além disso, todo um processo de degradação do solo, perda de biodiversidade e de conhecimentos locais foi desencadeado.

Apesar do imperativo de práticas agrícolas de monoculturas em larga escala, notamos que no Cerrado, as sementes crioulas ainda resistem e representam uma das inúmeras práticas sociais desenvolvidas por indígenas e populações tradicionais como Quilombolas, Vazanteiros e, principalmente, Geraizeiros.

Estes povos, devido ao relativo isolamento e à necessidade de sobrevivência a partir dos recursos locais, aprenderam a conviver com os ecossistemas do Cerrado, praticando uma agricultura de pequena escala, complementada pela criação de animais e pelo extrativismo (CARVALHO, 2012, p. 16).

Portanto, estas sementes correspondem não apenas ao ciclo da vida, ecológico e alimentar, mas também são elementos da cultura e das relações sociais.

As comunidades tradicionais, indígenas, quilombolas ou de agricultores familiares, tem, em sua gênese, uma ampla rede de significados e saberes, que foram se consolidando através dos tempos em um processo conjunto de transformação e consolidação. À medida que as comunidades foram se transformando, foram, assim, alterando e moldando a agrobiodiversidade conforme suas exigências. Os produtos dessa interação, mais visíveis e emblemáticos, são as espécies que compõe a agrobiodiversidade local ou crioula. São notáveis pelas suas formas, tamanhos e funções diferenciadas, que fazem parte do conjunto de saberes desses povos (KAUFMANN, 2010, p. 16).

Assim, a multiplicação de sementes crioulas está fundamentalmente ligada à cultura e ao processo de reprodução social local e, sobretudo, à identidade de várias comunidades e sua íntima identificação e relação com a natureza" (BENTHIEN, 2010, p. 33). 
Um exemplo claro dessa relação identitária das sementes crioulas com povos tradicionais pode ser observado nas comunidades do campo localizadas na região Norte do Estado de Minas Gerais. Essas comunidades, de modo geral, têm uma relação mais profunda com o meio ambiente que vai além da sobrevivência, correspondem muito mais a seu modo de viver, existir e às suas identidades. Tanto que a identidade é constituída em comunidade, ou seja, resulta de sua origem associada ao trabalho com a terra e com a religiosidade (BRITO, 2012). Essas características configuraram as relações sociais de parentesco, amizade ou trabalho, demarcando-as a partir dos laços de fé e solidariedade (NOGUEIRA, 2009).

O Norte do Estado de Minas Gerais corresponde também a um rico repositório de sementes crioulas, sob os cuidados dos chamados guardiões, em bancos e casas de sementes particulares e comunitários. Guardiões e guardiãs de sementes, em todo o Brasil, cultivam espécies sob o risco de extinção de modo coletivo (KAUFMANN, 2010).

Assim, a produção dos povos e comunidades tradicionais não tem como único fim a venda de seus produtos no mercado. Suas práticas de plantio, criação, extrativismo, etc. são, em sua maioria, destinados ao consumo, às festas, aos ritos, etc. e baseiam-se estritamente em "relações de troca e solidariedade" (MPMG, 2012, p. 11) características que possibilitam a manutenção e perpetuação das sementes crioulas e mantêm a unidade/identidade do grupo.

\section{CONTEXTO DE PESQUISA E PERCURSO METODOLÓGICO}

Nossa experiência tem como contexto o curso de Licenciatura em Educação do Campo da Universidade Federal do Triângulo Mineiro (LECampo - UFTM) implantado em 2014 no campus Uberaba-MG com duas habilitações: Ciências da Natureza e Matemática. Ao longo desses cinco anos e meio de funcionamento, três turmas de licenciandos passaram pelo curso, com a formatura da primeira turma de egressos acontecendo em julho de 2018, turma esta que deu sua primeira contribuição para se pensar no tema das sementes crioulas como assunto nas aulas de Ciências da Natureza. Nossos educandos, em sua maioria, são trabalhadores, oriundos de famílias de pequenos agricultores, vindos das mais diversas regiões do país, entre elas: Triângulo Mineiro, Norte e Noroeste de Minas, Rondônia e Sul da Bahia.

A LECampo - UFTM, assim como outros cursos de Licenciatura em Educação do Campo, adota um regime de alternância entre o Tempo-Escola (TE - caracterizado por atividades na universidade) e o Tempo-Comunidade (TC - quando as atividades são realizadas nas comunidades dos educandos). A Alternância, muito mais do que uma metodologia para o gerenciamento dos espaços-tempos, se constitui em uma pedagogia. “[...] a Pedagogia da Alternância tem o trabalho produtivo como princípio de uma formação humanista que articula 
dialeticamente ensino formal e trabalho produtivo" (RIBEIRO, 2008, p. 30). Desse modo, o trabalho como uma prática social e cultural juntamente com a educação mantém entre si um vínculo identitário que caracteriza as práticas formativas na Educação do Campo. Nossos educandos carregam consigo marcas identitárias de suas formações, solicitam serem reconhecidos como sujeitos de saberes e assim, interrogam os dias de estudo na universidade, bem como os conteúdos científicos escolarizados frente aos quais sentem-se estrangeiros já que em poucos momentos dialogam com sua própria cultura. E é desse lugar de sujeitos produtores de conhecimentos e não como consumidores (ARROYO, 2014) que os educandos questionam, direta ou indiretamente, o currículo por eles experimentado nas aulas de Ciências da Natureza.

Assim, o tema das sementes crioulas emergiu do relato das experiências e práticas sociais de alguns dos licenciandos em Educação do Campo da primeira turma do curso, que vez ou outra traziam o conhecimento relacionado às sementes como ilustração de conteúdos escolares das ciências na sala de aula, especialmente nas disciplinas de Genética, Evolução e Botânica. Muito mais atentos ao diálogo de saberes do que as professoras que ali conduziam as aulas, os educandos da primeira turma da LECampo - UFTM apontavam uma ponte viável de diálogo intercultural entre o conhecimento tradicional oriundo de suas práticas sociais e o conhecimento ocidental da ciência.

Na LECampo-UFTM, tanto a disciplina de Genética e Evolução como a de Botânica possuem 75 horas-aula, sendo que cada um desses componentes conta com 45 horas-aula desenvolvidas quando os licenciandos estão na universidade (Tempo Escola) e o restante no período em que estão em seus locais de origem (Tempo Comunidade).

Atentas ao movimento disparado pelos educandos, num primeiro momento durante a disciplina de Genética e Evolução, iniciamos a inserção do tema sementes crioulas em aulas de ciências. Esse processo não foi imediato, mas demandou planejamento e amadurecimento das docentes, pois a intenção não era apenas destacar o caráter didático do tema para o ensino de ciências na Educação do Campo, o intuito maior era fazer presente a força pedagógica da realidade em que nossos educandos estão imbuídos: terra, trabalho, esforço humano, coletivo, produção da vida através da construção de valores, culturas e identidades (ARROYO, 2014). O esforço de integração dos saberes sobre as sementes crioulas em aulas iniciou-se pela busca e leitura de muitos materiais. Dentre as várias fontes e autores que nos ajudaram nesse processo, destacamos em especial o obra de Pat Roy Mooney (1987), "O Escândalo das Sementes: o Domínio na Produção de Alimentos”, que apesar de antiga e de se tratar de cenário internacional, estabelece claramente as interrelações entre o interesse econômico de grandes grupos industriais, os pacotes tecnológicos decorridos da Revolução Verde e as 
consequências destes para a questão da soberania alimentar, que está colocada em risco. A partir dessa obra, buscamos outras que nos ajudaram no entendimento da questão brasileira quanto ao sequestro do patrimônio genético agrícola em comunidades tradicionais.

Desse modo, o tema foi introduzido efetivamente, apenas para a segunda turma da LECampo - UFTM, quando da oferta da disciplina de Genética e Evolução, no segundo semestre de 2017, temática que permaneceu presente nas ofertas subsequentes da mesma disciplina percorrendo também as atividades da disciplina de Botânica, conforme síntese no Quadro 1 a seguir.

Quadro 1- Síntese das atividades com o Tema Sementes Crioulas.

\begin{tabular}{|c|c|c|c|}
\hline Semestre & Disciplina & Atividades & $\begin{array}{c}\text { Carga } \\
\text { Horária } \\
\text { destinada }\end{array}$ \\
\hline $2017 / 1$ & $\begin{array}{l}\text { Genética e } \\
\text { Evolução }\end{array}$ & Emergência do Tema. & $0 \mathrm{~h} / \mathrm{a}$ \\
\hline $2017 / 2$ & $\begin{array}{l}\text { Genética e } \\
\text { Evolução }\end{array}$ & 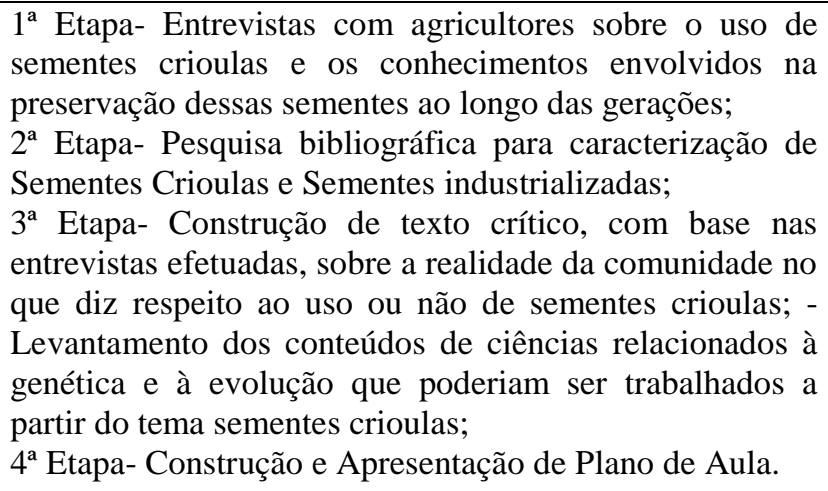 & $\begin{array}{c}\mathrm{TC} \\
\mathrm{APC}^{1} 15 \\
\mathrm{~h} / \mathrm{a}\end{array}$ \\
\hline $2018 / 1$ & Botânica Geral & 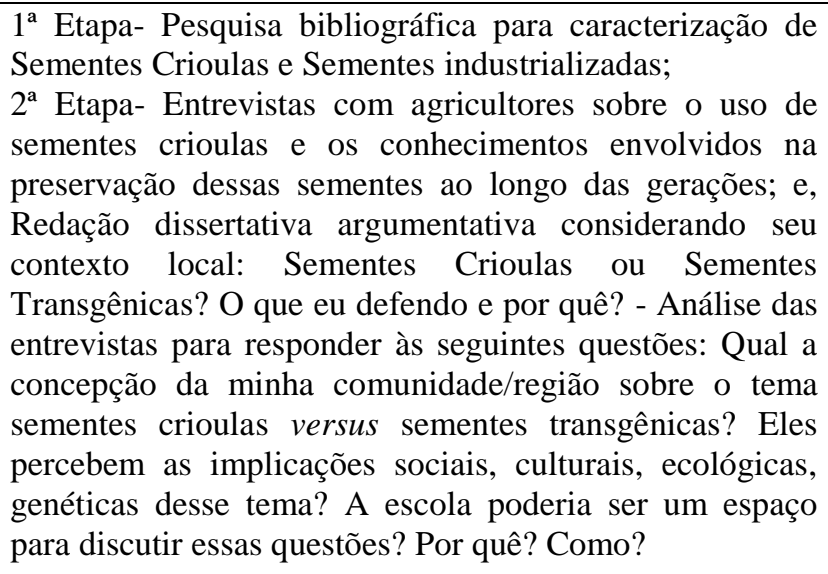 & $\begin{array}{c}\text { APC } 15 \\
\text { h/a }\end{array}$ \\
\hline $2018 / 2$ & $\begin{array}{l}\text { Genética e } \\
\text { Evolução }\end{array}$ & Diversas ao longo de toda a disciplina. & $\begin{array}{c}\mathrm{TE}+\mathrm{TC} \\
75 \mathrm{~h} / \mathrm{a}\end{array}$ \\
\hline
\end{tabular}

Fonte: Dos autores.

Neste contexto, os dados analisados a seguir são resultados do trabalho de pesquisa dos docentes pertencentes ao Grupo de Estudos e Pesquisas da UFTM: Integração de Saberes na Formação de Professores de Ciências para o Campo. O trabalho, de natureza qualitativa (CRESWELL, 2014), consiste na análise de situações de ensino em que a temática sementes

\footnotetext{
${ }^{1}$ Atividade Prática Curricular (APC) atualmente reconhecida como Prática como Componente Curricular (PCC) na instituição. 
crioulas foi integrada aos conteúdos de ciências. Tal análise, mediada por Arturo Argueta (2015), objetiva, entre outras coisas, evidenciar nestas práticas docentes pontos de articulação ou desarticulação da temática sementes crioulas aos conteúdos do Ensino de Ciências.

\section{UMA EXPERIÊNCIA CONCRETA DA ARTICULAÇÃO DO TEMA SEMENTES CRIOULAS EM SITUAÇÕES DE ENSINO NA FORMAÇÃO DE PROFESSORES PARA O CAMPO}

As situações concretas de ensino aqui apresentadas correspondem à exercícios de análise sobre a própria prática de docentes ao longo da oferta das disciplinas de Genética e Evolução e Botânica, no contexto do curso de Licenciatura em Educação do Campo da UFTM, tendo suas práticas voltadas à perspectiva da Integração de Saberes. Ressaltamos que a análise não teve como intenção debruçar-se sobre fontes documentais como as atividades desenvolvidas com os alunos no contexto destas disciplinas, embora alguns discursos sejam trazidos para ilustrar argumentos, mas, sobre as ações ou conteúdos que demonstraram a possibilidade ou não de articulação com os conhecimentos tradicionais advindos dos alunos e suas comunidades acerca da temática sementes crioulas.

Vale destacar ainda que os conhecimentos que adjetivamos como tradicionais são constituídos e se constituem em práticas sociais de sobrevivência e existência de povos e comunidades tradicionais. Trata-se de um discurso que se opõe como resistência (epistemológica) aos processos de colonização tal como a ideologia da modernização conservadora, da "promessa" de progresso e desenvolvimento, comumente propagada pelo agronegócio (ALENTEJANO, 2003; SILVA, 2015).

\footnotetext{
Não por ser patrimonialmente uma guardiã do passado, ou por ser expressivamente "folclórica", "típica" ou um "genuíno exemplo de nossas mais preciosas tradições", uma comunidade popular (mas nem todas elas) é também tradicional. Ela o é por representar uma força ativa e presente de resistência à quebra de um reduto interhumano de relações ainda centradas mais em pessoas e rede de reciprocidade de/entre sujeitos-atores através de produto do trabalho, do que em coisas e trocas de mercadorias através de pessoas, tornadas elas próprias, seres-objeto. (BRANDÃO, 2012, p. 373).
}

Há, portanto, uma relação indissociável entre os conhecimentos tradicionais e as práticas sociais desenvolvidas em comunidades, no nosso caso, as do campo. Cabe reafirmar a dimensão social dessas práticas uma vez que sua recorrência não se dá de modo arbitrário, neutro e isolado. Pelo contrário, práticas sociais são ideológicas, têm sua história, estão envolvidas em relações de poder e fazem parte do mundo simbólico e cultural das suas comunidades de origem. Ou seja, a prática social da guarda de sementes crioulas não se explica sozinha, tampouco pelos agricultores que desempenham essa função, mas sim, só 
podemos compreender a atividade dos guardiões de sementes ${ }^{2}$, por exemplo, do semiárido mineiro, levando em conta a luta pela terra e por água, os conflitos com os empreendimentos da monocultura do eucalipto, a agricultura familiar e a afirmação dos direitos dos povos do campo.

No que diz respeito às pontes interculturais entre os diferentes tipos de conhecimento, Arturo Argueta (2015) sistematiza três modos de tratamento, ou como o autor diz: afirmações, quanto às relações entre conhecimentos indígenas e científicos que aqui assumimos e transpomos para os conhecimentos tradicionais, quando se supõe sua convergência, sua divergência ou que eles são paralelos.

$\mathrm{Na}$ convergência entre os conhecimentos tradicionais e científicos há uma articulação utilitária, instrumental e subordinada à lógica da ciência ocidental que acaba por operar uma espécie de dissolução dos saberes tradicionais à ciência canônica. Em outras palavras, é o que frequentemente temos visto na literatura com relação ao tratamento do saber sobre as plantas medicinais, por exemplo. Os saberes tradicionais sobre as plantas medicinais, quando resgatados, acabam sendo desconfigurados na medida em que a aplicação dos princípios de uma planta por determinada comunidade passa a ser questionada pela ciência. Tal esvaziamento daquele saber desequilibra a articulação tensionando para sua validade apenas sob os óculos da ciência.

Enquanto na afirmação da divergência tem-se como marca a impossibilidade do diálogo sob o ponto de vista de ambos os conhecimentos. De um lado, pretende-se preservar os sistemas de saberes não-ocidentais destacando suas formas próprias de explicitação e que um estrangeiro àquela cultura jamais será capaz de conhecê-los. Do ponto de vista do conhecimento ocidental, científico, por outro lado, ocorre o mesmo fechamento por compreender que se tratam de sistemas de conhecimentos incomensuráveis, e que, portanto, não são conciliáveis. Aqui, mesmo que se busque a proteção e o fortalecimento interno dos conhecimentos tradicionais visando seu reconhecimento e valorização, esta perspectiva acaba por contribuir para o fechamento ao diálogo, quase impossível, no contexto da sociedade contemporânea marcada pelas globalizações.

No paralelismo complementar os conhecimentos tradicionais têm suas especificidades reconhecidas, suas epistemologias, mas eles são capazes de abrir-se ao diálogo e articular-se pontualmente buscando bases claramente definidas e espaços não subordinados. Os conhecimentos tradicionais podem articular-se aos conhecimentos científicos em problemas de interesse mútuo, frente a desafios concretos relacionados à alimentação, à saúde, à moradia, ao uso do solo, à disponibilidade de água, à conservação da

${ }^{2}$ Lideranças comunitárias responsáveis por plantar, colher, guardar e distribuir sementes nativas e crioulas. 
biodiversidade, ao trabalho, entre outros, criando pontos de contato que favoreçam o enriquecimento de ambos, no entanto são capazes também de desarticular-se passado o momento de interesse comum.

O diálogo de saberes nessa perspectiva tem uma utilidade específica e obteria grandes contribuições, pois se almeja que os Sistemas de Saberes Indígenas [tradicionais] estabeleçam pontos de articulação e comparabilidade no diálogo universal de saberes; que se coloquem os desafios de construção de uma tradição; que se estruturem como poder para a tomada de decisões que os afetam; e persistir no contexto do conjunto das outras tradições, em suma, constituir-se em uma tradição formalizada num campo conjunto com as demais tradições. Nesse sentido, é inadiável a tarefa de constituir-se como conhecimentos explícitos, que se conhecem o poder de seu saber e o expressem frente a outros saberes. (ARGUETA, 2015, p. 191).

A partir destas reflexões nossa análise debruça-se num primeiro momento sobre a experiência de integração do tema sementes crioulas na disciplina de Genética e Evolução ao longo do segundo semestre de 2017 (QUADRO 1).

Observamos que o tema não tinha tanta representatividade para esta turma. Os estudantes, em sua maioria residentes em territórios no Triângulo Mineiro, demonstraram em suas pesquisas de modo geral o desconhecimento em suas comunidades/localidades de origem com relação ao tema sementes crioulas bem como sua preservação.

Notamos o forte domínio do agronegócio nas práticas de plantio, cultivo e subsistência. Nesse sentido, a preservação do patrimônio genético e cultural das sementes foi muitas vezes reconhecido pelos estudantes como estranho ao contexto em que viviam. Apesar disso, os estudantes desta turma conseguiram articular pontos importantes como a questão da soberania alimentar e o papel político, econômico e cultural que os guardiões de sementes desempenham, em propostas de ensino construídas por eles em sala de aula.

Tendo em vista as afirmações de Argueta (2015), assumimos a posição do paralelismo complementar e consideramos que as atividades propiciadas nesta disciplina apresentaram pontos de contato e pontos de afastamento entre os conhecimentos tradicionais e científicos.

Os pontos de afastamento se deram mais explicitamente na primeira etapa da atividade - Entrevistas nas comunidades de origem - já os pontos de contato se mostraram mais aparentes nas demais atividades da turma de 2017/2 (QUADRO 1).

Segundo Argueta (2015), o paralelismo complementar se caracteriza por momentos em que é possível e cabível a articulação para resolução de problemas de interesses mútuos, ela se dá, passada essa fase, ou não havendo questões em comum a serem resolvidas, acontecem os afastamentos. Neste caso específico, a desarticulação da temática das sementes crioulas com o contexto de vida das comunidades, não permitiu que ocorressem pontos de contato na primeira etapa da atividade. Parte desse resultado se deve ao tema sementes 
crioulas não ser um elemento cultural para algumas das comunidades/ territórios desses estudantes. Dito de outro modo, os alunos do Triângulo Mineiro, por exemplo, nem sempre apresentam um vínculo identitário forte com a terra, muito menos a noção de comunidade quando comparada a outras regiões mais tradicionais, no que diz respeito à cultura e modos de vida, por estarem inseridos em regiões predominantemente urbanas. Conforme relatou uma das licenciandas:

"[...] a falta de conhecimento sobre as sementes crioulas é bem assustadora. Além da entrevista que fiz com o ((morador de Veríssimo)), perguntei para várias pessoas a respeito das sementes crioulas, e todas que perguntei não sabiam nada a respeito, muitos até riam pelo nome citado" (Aluna $1,6^{\circ}$ período em 2017-2).

Ao mesmo tempo, a atividade desenvolvida em suas etapas seguintes nos possibilitou, enquanto formadores de professores, notarmos que há sim vários pontos de encontro entre a temática proposta e os conhecimentos científicos, por propor a manutenção das especificidades de cada tipo de conhecimento ao mesmo tempo em que os articula pontualmente em bases definidas e espaços não-subordinados a um ou a outro conhecimento (ARGUETA, 2015). Foi possível com a construção do texto da pesquisa bibliográfica (2a etapa) e texto crítico ( $3^{\mathrm{a}}$ etapa), culminando na aula apresentada ( $4^{\mathrm{a}}$ etapa), notar que no Ensino de Ciências cabe trabalhar ambas perspectivas de conhecimento de maneira não subordinada e igualitária, através da complementaridade paralela entre os saberes. Esse olhar complementar é que nos aproximou um pouco mais, inclusive, da realidade de desaparecimento dessa prática social de manejo das sementes crioulas em algumas comunidades e despertou nosso olhar para o perigo eminente que nos ronda de desaparecimento desse material cultural, histórico e genético em alguns contextos, fato que é reforçado por posições como a divergente ou convergente, apresentadas por Argueta (2015).

No semestre seguinte (2018/1), o tema percorreu também a disciplina de Botânica. A turma, agora predominantemente relacionada à vida e trabalho com o campo, cujos alunos são em sua grande maioria do Norte do Estado de Minas Gerais, demonstrou-se mais promissora ao desenvolvimento, desde o início da atividade, do ponto de vista do paralelismo complementar visto que grande parte desses alunos vivenciam uma estreita relação com as sementes crioulas, seja por guarda própria efetuada pela família, plantio ou existência de bancos de semente na comunidade.

Como pode ser visto nas atividades propostas (QUADRO 1), na disciplina de Botânica tentamos aproximar um pouco mais dos saberes que envolvem as sementes quando em comunidades tradicionais como um todo, ou seja, procurando compreender a realidade local como contexto de pesquisa. Resultado daquilo que nos alertou o exercício efetuado com a turma anterior. 
A experiência nesta disciplina foi gratificante, pois outras nuances sobre a temática, inexistentes até então para o conhecimento da docente ministrante foram trazidas e discutidas pelos estudantes do campo, tais como: os inúmeros nomes atribuídos às sementes crioulas, os processos de perda e de retomada das sementes pelas comunidades, as diferentes formas de preservação, a relação das sementes com a identidade local, a relação das sementes com a falta d'água, entre tantos outros aspectos.

Avaliamos que, nesta turma, a articulação do tema ocorreu ao longo de toda a atividade, possibilitando o enriquecimento da formação docente dos alunos da Educação do Campo na medida em que revisitaram uma prática social do seu cotidiano com outro olhar que permitiu fortalecer os conhecimentos envolvidos com o uso e preservação das sementes não apenas do ponto de vista cultural mas também ambiental, social e econômico. A atividade ainda contribuiu para vislumbrar novas e possíveis articulações com a ciência escolar para a resolução de problemas de interesse mútuo.

Dessa última experiência com o tema sementes crioulas em sala de aula, nasceu: i) um projeto de iniciação científica com bolsa, desenvolvido por um licenciando desta turma com o objetivo de investigar a tradição de plantio e guarda das sementes crioulas e suas relações com o solo, a chuva, seca, ou seja, com o território (FERREIRA; CREPALDE; KLEPKA, 2019), ; e ii) um trabalho de conclusão de curso sobre as variedades de sementes crioulas perdidas e resgatadas na e pela comunidade (SANTOS, 2019). Todos esses desdobramentos têm como locus o Norte do Estado de Minas Gerais. Nesse sentido, salientamos que o tema também vem contribuindo para trazer discussões e pesquisas dentro do grupo de pesquisa Integração de Saberes na Formação de Professores do Campo. O fator interessante nestas experiências é que embora a proposta inicial tenha partido das docentes, seus desdobramentos e como continuidade dessa experiência compartilhada, trata-se de um tema recorrente na vida desses licenciandos do campo, o que faz com que o interesse posterior em desenvolver artigos, TCC's e iniciações científicas sejam uma continuação natural da conversa que o tema das sementes crioulas, a partir dessa abordagem complementar, tornou possível com a realidade desses educandos.

Nossa última e mais recente experiência com o tema de ensino ocorreu também nesta terceira turma no segundo semestre de 2018, durante a disciplina de Genética e Evolução. Diferentemente das outras duas experiências, nesta, as professoras utilizaram do tema sementes crioulas ao longo de toda a disciplina discutindo e tecendo relações com o conteúdo científico quando possíveis. Portanto, efetiva-se nesta disciplina alguns casos concretos nos quais os conhecimentos acerca das sementes crioulas puderam ser articulados ou desarticulados em situações de ensino para a formação de professores do campo. 
Procuramos esquematizar no quadro 2, o acúmulo das professoras quanto aos tópicos possíveis de serem trabalhados sobre o tema sementes crioulas (conhecimento tradicional) ao longo das experiências com as disciplinas anteriores e sua culminância em articular-se ou não (no centro) com alguns conteúdos científicos e interdisciplinares tratados na disciplina de Genética e Evolução, ministrada em 2018/02 (à direita). Cabe ressaltar que os conhecimentos que são listados acerca das sementes crioulas são resultados de pesquisas para fins de ensino decorrentes de contextos bem definidos, ou seja, moradores do campo cujas práticas de plantio e cultivo se baseiam nesse tipo de sementes. Outros e diferentes contextos podem agregar mais tópicos a esta lista bem como suprimir alguns deles em virtude da particularidade de cada local.

Chamamos atenção dentre as experiências de articulação apontadas (QUADRO 2) para dois momentos em específico. Aqueles que chamamos de articulações efetuadas para o tratamento de problemas de interesse mútuo de ambos os sistemas de conhecimento $(\leftrightarrow)$ e aquelas articulações pontuais realizadas para fins de ensino $(\rightarrow)$.

Quadro 2 - Paralelismo Complementar do tema sementes crioulas em situações de ensino para a formação de professores

\begin{tabular}{|c|c|c|}
\hline Conhecimento Tradicional & $\begin{array}{c}\text { Paralelismo } \\
\text { Complementar }\end{array}$ & Conhecimento Científico \\
\hline $\begin{array}{c}\text { Nomes populares } \\
\text { (sementes crioulas, sementes negras, } \\
\text { sementes das famílias, etc.) }\end{array}$ & - & Nomes científicos \\
\hline $\begin{array}{c}\text { Espécies de sementes crioulas cultivadas e } \\
\text { suas variedades }\end{array}$ & $\rightarrow$ & Espécies e variedades na Botânica \\
\hline Guardiões de sementes & $\leftrightarrow$ & Patenteamento de sementes \\
\hline Bancos de Sementes Comunitários & $\leftrightarrow$ & Bancos de Sementes Empresariais \\
\hline Domesticação de espécies & $\rightarrow$ & Seleção Artificial \\
\hline $\begin{array}{l}\text { Alta variabilidade e baixo número de } \\
\text { sementes }\end{array}$ & $\rightarrow$ & Genética de Populações \\
\hline Perda de Sementes & $\leftrightarrow$ & Migração, Fluxo Gênico \\
\hline Variabilidade & $\rightarrow$ & Mutação Genética \\
\hline Cuidado com o meio ambiente & $\leftrightarrow$ & Agronegócio e Transgenia \\
\hline Falta d'água, resistências naturais & $\leftrightarrow$ & Adaptação Biológica \\
\hline Feira de Troca de Sementes & $\rightarrow$ & Efeito fundador \\
\hline Cultura, tradição, usos e preservação & $\leftrightarrow$ & $\begin{array}{l}\text { Manutenção do patrimônio genético e } \\
\text { cultural e suas implicações sociais }\end{array}$ \\
\hline
\end{tabular}

Fonte: Dos Autores. Legenda: $(\leftrightarrow)$ indica articulações efetuadas para o tratamento de problemas de interesse mútuo dos sistemas de conhecimento; $(\rightarrow)$ representa articulações pontuais realizadas para fins de ensino; $(-)$ indica ausência de articulação.

A primeira, mais ampla, paralela e complementar guarda em suas devidas proporções as especificidades de cada um dos sistemas de conhecimento e articulam-se justificadamente. 
Por exemplo, a perda de sementes é um processo que vem sendo constatado há alguns anos em determinadas comunidades do Norte do Estado de Minas Gerais, conforme acompanhamos em pesquisas finalizadas. São inúmeros os fatores que a desencadeiam. Para citar alguns, temos: o desequilíbrio ambiental causado pela monocultura; novos hábitos de plantio e cultivo influenciados pelo agronegócio; mudanças climáticas acarretando falta de chuvas; entre tantos outros. Do ponto de vista da ciência escolar, um dos conteúdos que podem dialogar com esse processo de perda dentro da disciplina de Genética e Evolução é o de migração e fluxo gênico. Mas estes não seriam os únicos, assim como não podemos pensálos como mecanismos neutros e isolados, eles fazem parte de um núcleo maior de situações que provocaram e mantém a perda de determinadas sementes na comunidade.

Nesta experiência, por exemplo, destacamos a possibilidade de perda em decorrência do êxodo rural que retirou muitos agricultores de suas terras, guardiões de sementes repassadas por antepassados, mas que não foram trocadas (ausência de fluxo gênico, troca de material genético entre os indivíduos por meio de cruzamentos) com outras variedades. A articulação de ambos esses conhecimentos promove não apenas a compreensão dos mecanismos evolutivos dentro da Biologia aplicados ao caso das sementes, como também permite ao estudante do campo, futuro professor, compreender a relevância do processo de guarda comunitária e troca de sementes entre os moradores.

O segundo tipo de articulação pontual e transitória é demarcada por sua realização para fins de ensino. Elas podem ocorrer de formas diversas e em espaços que vão além da sala de aula formal. Um exemplo claro que trabalhamos nas aulas de Genética e Evolução e que promoveu inclusive outras articulações foi a domesticação efetuada pelos povos tradicionais e seu correspondente nos termos científicos: a seleção artificial de caraterísticas de interesse. Para isso o caso do milho foi estudado como fechamento das aulas em Tempo Escola, transitando em ambas as disciplinas de modo concomitante e interdisciplinar: domesticação do milho; seleção artificial; cálculo de frequências alélicas e genotípicas de interesse para o tamanho da espiga e Lei de Hardy-Weinberg. Todos esses conteúdos dialogaram com o tema sementes crioulas de modo a demonstrar o compartilhamento de material genético entre variedades distintas; a ancestralidade; o papel da seleção de características de interesse de domesticação no atual fenótipo da espiga de milho; a discussão crítica do melhoramento laboratorial; a resistência natural das espécies; a questão da patente das sementes como proteção ou restrição à biodiversidade; e, principalmente, o ensino dos conteúdos genéticos a partir do olhar para as consequências genéticas e evolutivas a partir de um contexto real: o plantio apenas de milho industrializado (monocultura) versus o plantio tradicional de sementes crioulas, onde a quantidade de indivíduos difere-se em número e variabilidade 
genética buscando demonstrar por meio dos números porque a variabilidade genética é maior na população de milho crioulo mesmo contendo menos indivíduos, o que ressalta a importância das sementes crioulas sob a guarda dos povos tradicionais.

Como síntese da disciplina de Genética e Evolução, os estudantes organizaram uma feira de troca de sementes crioulas, ocorrida no Tempo Escola em janeiro de 2019, totalmente planejada e executada pelos alunos da turma com o objetivo de mostrar para a comunidade universitária e também à comunidade externa à UFTM a importância do tema para a sociedade e em nosso curso; apresentar ainda como os povos e sujeitos do campo contribuem para a discussão do tema e manutenção dessas sementes tão imprescindíveis à diversidade de cultivos. Além disso, acreditamos que a troca pode estimular, mesmo que entre os próprios estudantes, o processo de compartilhamento e manutenção do material genético, assim como a manutenção de uma prática social que muito contribui para o alicerce identitário e, portanto, permitindo a preservação de sua tradição cultural e também da variabilidade genética das espécies.

\section{CONSIDERAÇÕES FINAIS}

Dentre os inúmeros e variados tipos de relações entre os conhecimentos tradicionais e o científico, as que mais comumente vemos explícitas no Ensino de Ciências são as relações pautadas pela lógica da convergência e divergência, citadas por Argueta (2015). Relações convergentes onde o conhecimento tradicional está subordinado ao científico, sujeito ao silenciamento, única saída que lhe resta. Relações divergentes pautadas na afirmação das diferenças abissais entre os conhecimentos, impossibilitando o possível enriquecimento mútuo entre conhecimentos e contribuindo para a compreensão dos saberes tradicionais como algo exótico ou folclórico.

Essa forma abissal de pensar o conhecimento é segregadora e traspassa o pensamento pedagógico: Como abrir os espaços/latifúndios do saber àqueles coletivos que vivem e reproduzem suas existências ou inexistências do outro lado da linha onde não há conhecimento real, mas apenas crendices? (ARROYO, 2014, p. 214)

Entretanto, ainda que a ciência canônica insista em negar e silenciar os saberes produzidos pelos sujeitos do campo, reproduzindo uma concepção segregadora dos conhecimentos, chamada por Arroyo (2014) de antipedagógica, é preciso que nós, os professores formadores, assumamos uma postura de não segregar por completo os conhecimentos. Nosso papel enquanto formadores de professores para o campo é de "ir além da classificação de uns coletivos como racionais e os outros como irracionais, sem saberes ou atolados na ignorância e nas falsidades” (ARROYO, 2014, p. 214). 
As lições que tiramos a partir dos dizeres de Argueta (2015) e de nossa experiência concreta na disciplina de Genética e Evolução ao longo do segundo semestre de 2018, na qual os conhecimentos acerca das sementes crioulas puderam ser articulados ou desarticulados em situações de ensino para a formação de professores do campo é que a apropriação mútua entre sistemas de conhecimentos faz sentido se a mesma propiciar uma nova síntese dentro de cada uma delas, pois constitui-se de um processo, um relacionamento. Desse exercício analítico sobre a própria prática, algumas reflexões inspiradas no autor reforçam a importância e o potencial da articulação paralela e complementar na formação inicial de professores para o campo:

i) ao aproximarmos de um sistema de conhecimento, ter em mente nosso pequeno ou nenhum conhecimento sobre seu funcionamento. Desse modo, transpô-lo para a sala de aula perpassa primeiramente por estudá-lo e compreendê-lo sempre mais, cientes de que nunca saberemos tudo;

ii) todos os conhecimentos tradicionais estão imersos em elementos culturais que se articulam sob diferentes frentes formando um todo que só pode ser compreendido em todas as suas dimensões. Disso resulta que ao tratar em paralelo um conhecimento não devemos fragmentá-lo ou isolá-lo de seus contextos sociais, políticos, econômicos etc.

iii) a articulação que se propõe ser paralela e complementar deve contribuir para pensar em alternativas, resoluções para desafios atuais de interesse mútuos para ambos os sistemas de conhecimento.

Defendemos a integração de saberes tradicionais originados das práticas sociais dos sujeitos do campo à formação de professores de ciências para o campo e nesse texto mostramos que tal integração é possível a partir da temática das sementes crioulas. Reconhecendo esses saberes como legítimos dos povos do campo e válidos para situações de ensino a partir de contextos delimitados. Para tanto, entendemos que uma postura mais próxima do paralelismo complementar seja a mais adequada por, de um lado assumir, quando possível, aproximação e complementaridade entre os sistemas de conhecimento, e por outro lado reconhecer que há pontos de distanciamentos em que os sistemas de conhecimento caminharão em paralelo. Assumimos que esta postura tem "maior potencial para cooperação baseada em respeito mútuo entre comunidades tradicionais e comunidades científicas, preservando a autonomia dos processos de produção de conhecimento e buscando possibilidades de diálogo e complementaridade” (EL-HANI, 2018, p. 06). 


\section{REFERÊNCIAS}

AIKENHEAD, G.; MICHELL, H. Bridging Cultures: indigenous and scientific ways of knowing nature. Toronto: Pearson, 2011.

ALENTEJANO, P. R. R. As relações campo-cidade no Brasil do século XXI. Terra Livre, São Paulo, v. 2, n. 21, p. 25-39, ano 18, jul./dez. 2003.

ALVARENGA, A. C.; DAYRELL, C. A.; VERNOOY, R.; SHRESTHA P.; STHAPIT, B.; RAMÍREZ, M. (Eds). Bancos Comunitarios de Semillas: Orígenes, Evolución y

Perspectivas. Bioversity International, Lima, Perú. 1ª ed., 2016.

AMORIM, L. O.; OLIVEIRA, L. C.; CURADO, F. F.; SANTOS, A. S. Troca de saberes como estratégia de formação e valorização das sementes crioulas: a ação do movimento de pequenos agricultores (MPA) em Poço Redondo, Sergipe, Brasil. V Congreso Latinoamericano de Agroecología. La Plata, Argentina, 2015.

ARGUETA, A. Os saberes e as práticas tradicionais: conceitos e propostas para a construção de um campo transdisciplinar. In UDRY, C.; EIDT, J. S. (Ed.). Conhecimento tradicional: conceitos e marco legal. Brasília: Embrapa, 2015.

ARROYO, M. Outros Sujeitos, Outras Pedagogias. Petrópolis, RJ: Vozes, 2014.

BENTHIEN, P. F. Transgenia Agrícola e Modernidade: um estudo sobre o processo de inserção comercial de sementes transgênicas nas sociedades Brasileira e Argentina a partir dos anos 1990. 272 f. (Tese-doutorado) Universidade Estadual de CampinasUNICAMP, Campinas, SP: 2010.

BRANDÃO, C. R. A comunidade tradicional. In: COSTA, J. B. A.; OLIVEIRA, C. L. Cerrados, Gerais, Sertão: comunidades tradicionais nos sertões roseanos. São Paulo: Intermeios; Belo Horizonte: FAPEMIG; Montes Claros: Unimontes, 2012.

BRITO, I. C. B. Geraizeiros em movimento. In: COSTA, J. B. A.; OLIVEIRA, C. L. Cerrados, Gerais, Sertão: comunidades tradicionais nos sertões roseanos. São Paulo: Intermeios; Belo Horizonte: FAPEMIG; Montes Claros: Unimontes, 2012.

BUSTAMANTE, P. G.; ALVARENGA, A. C.; LOPES, N. F. A. Gestão compartilhada da agrobiodiversidade: Sementes: estratégias articuladas em rede. In: ALVARENGA, A. C.; DAYRELL, C. A.; FÁVERO, C.; MONTEIRO, F. T.; MOREIRA, G. D.; ROSA, H. S. (Org.). Agrobiodiversidade: uso e gestão compartilhada no semiárido mineiro. 1ed. Montes Claros: CAA/NM, 2014, v. 1, p. 22-27.

CARVALHO, I. S. H. Assentamento Americana e Grupo Agroextrativista do Cerrado: uma experiência agroecológica no Norte de Minas. Brasília/ DF - Grão Mogol/ MG. Instituto Sociedade, População e Natureza (ISPN)/ Grupo Agroextrativista do Cerrado. Brasil, 2012.

CIMOS/MPMG (Coordenadoria de Inclusão e Mobilização Sociais - Ministério Público de Minas Gerais. Direitos dos povos e das comunidades tradicionais. Disponível em: https://caa.org.br/media/publicacoes/PUBLICACAO_ESPECIAL_DIREITOS_DOS_POVOS E_COMUNIDADES_TRADICIONAIS_oibAP6o.pdf. Acessado em agosto de 2018. 
CREPALDE, R. S.; KLEPKA, V.; HALLEY, T. O. P. Interculturalidade e conhecimento tradicional sobre a Lua na formação de professores no/do campo. Revista Brasileira de Educação do Campo, 2(3), 836-860, 2017.

CREPALDE, R. S.; KLEPKA, V.; HALLEY, T. O. P.; SOUSA, M. A integração de saberes e as marcas dos conhecimentos tradicionais: reconhecer para afirmar trocas interculturais no ensino de ciências. Revista Brasileira de Pesquisa em Educação em Ciências, 19, p. 275297, 2019.

CRESWELL, J. W. O projeto de um estudo qualitativo. In: Investigação qualitativa e projeto de pesquisa: escolhendo entre cinco abordagens. Porto Alegre: Penso, 2014.

EL-HANI, C. Integrando conhecimentos científicos e tradicionais na conservação. 2018. Disponível em: https://darwinianas.com/2018/05/01/integrando-conhecimentos-cientificos-etradicionais-na-conservacao/. Acessado em setembro de 2018.

FERREIRA, M. S.; CREPALDE, R.S.; KLEPKA, V. O saber das comunidades tradicionais

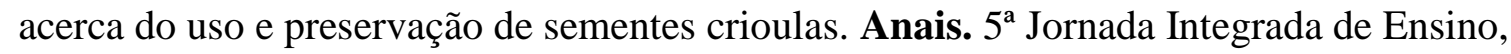
Pesquisa e Extensão - JIEPE - UFTM, Uberaba- MG, 2019. Disponível em: <http://www.uftm.edu.br/jiepe/anais/2019> Acesso em 16 de agosto de 2020.

KAUFMANN, M. P. Resgate, conservação e multiplicação da agrobiodiversidade crioula: um estudo de caso sobre a experiência dos guardiões das sementes crioulas de Ibarama (RS). 116 f. (Dissertação- Mestrado). Universidade Federal de Santa Maria, Rio Grande do Sul, 2014.

MOONEY, P. R. O Escândalo das Sementes: o Domínio na Produção de Alimentos. São Paulo: Nobel, 1987.

MPMG, Ministério Público de Minas Gerais. Coordenadoria de Inclusão e Mobilização Sociais (CIMOS). Direitos dos Povos e Comunidades Tradicionais. Minas Gerais, 2012.

NOGUEIRA, M. C. R. Gerais a dentro e afora: identidade e territorialidade entre os Geraizeiros do Norte de Minas Gerais. Tese de Doutorado em Antropologia Social. Brasília: Universidade de Brasília (UnB), 2009.

OLIVEIRA, E. L. Conservação de base comunitária de sementes crioulas: a experiência da Casa de Sementes de Barra do Tamboril, Januária/MG. 112f. Dissertação (Mestrado em Meio Ambiente e Desenvolvimento Rural). Universidade de Brasília. 2014.

PEREIRA, L. S.; BARBOSA, G. G., AGUILAR, P. A. P.; TEIXEIRA, R. D. B. L.; SOLDATI, G. T.; SCHAEFFER, C. E.; COELHO, F. M. G. Cartilha 8: Catálogo de registro: casa de semente do seu Geraldo Gomes. Viçosa, MG: Universidade Federal de Viçosa; MEC/SESu, 2016. (Coleção Norte de Minas) 31 p.

PORTO-GONÇALVES, C. W. Descolonizar o pensamento, condição para a sustentabilidade: diálogo com Carlos Walter Porto-Gonçalves. Sustentabilidade em Debate, 5(3), 159-168, 2014.

RIBEIRO, S. Camponeses, biodiversidade e novas formas de privatização. In: CARVALHO, H. M. (orgs). Sementes: patrimônio do povo a serviço da humanidade. São Paulo: Editora Expressão Popular, 2003. p. 51-72. 
RIBEIRO, M. Pedagogia da alternância na educação rural/do campo: projetos em disputa. Educação e Pesquisa, São Paulo, v.34, n.1, p. 27-45, jan./abr. 2008.

REZENDE, A.; MIRANDA, C. T.; FRAGA, K. S.; NOVATO, T. S.; SOLDATI, G. T. Resgate de sementes crioulas como estratégia para a soberania alimentar e nutricional no assentamento Dênis Gonçalves, Minas Gerais. Anais XI Simpósio Brasileiro de Etnobiologia e Etnoecologia/I Festival de Sementes Crioulas da Bahia - Feira de Santana/BA -22 a 26 de novembro de 2016.

SANTOS, T. M. M.; DE ANDRADE, L. O.; MEDEIROS, D. S. Avaliando a metodologia de ensino de conteúdo agroecológico através da literatura em formato de cordel. Resumos do VIII Congresso Brasileiro de Agroecologia - Porto Alegre/RS - 25 a 28 de novembro de 2013. Cadernos de Agroecologia - ISSN 2236-7934 - v.8, n.2, p.1-3, nov. 2013.

SANTOS, U. O. As variedades crioulas do Projeto de Assentamento Agroextrativista Veredas Vivas - Comunidade Tradicional Vereda Funda, Norte de Minas Gerais. $60 \mathrm{f}$. Trabalho de Conclusão de Curso (Licenciatura em Educação do Campo/ Ciências da Natureza) Universidade Federal do Triângulo Mineiro, Uberaba-MG, 2019.

SILVA, A. T. R. A conservação da biodiversidade entre os saberes da tradição e a ciência. Estud. av., São Paulo, v.29, n.83, p. 233-259, abr. 2015.

SILVA, N. C. A. Manejo da diversidade genética de milho como estratégia para a conservação da agrobiodiversidade no Norte de Minas Gerais. 136 f. Dissertação (Mestrado em Ciências Agrárias, área de concentração em Agroecologia) Universidade Federal de Minas Gerais, 2011.

SILVA, N. C. A.; ROCHA, G. P.; ALVARENGA, A. C.; FRANÇA, R.; LOPES, N. F. A.; TEIXEIRA, T. S.; BRANDÃO JÚNIOR, D. S. Conhecendo e Resgatando a Diversidade Genética de Milho, no Assentamento Vale do Guará, Norte de Minas Gerais. Rev. Bras. de Agroecologia. v. 4, n.2, 2009a.

SILVA, N. C. A.; TEIXEIRA, T. S.; LOPES, N. F. A.; BRADÃO JUNIOR, D. S.; ALVARENGA, A. C.; ROCHA, G. P. Ensaio Regional de Milho Crioulo: Estratégia Participativa para a Conservação e o Manejo da Agrobiodiversidade no Norte de Minas Gerais. Rev. Bras. de Agroecologia. v.4, n.2, 2009 b.

SILVA, M. J. R.; MARINI, F. S.; PAULA, A. C.; COELHO, A. A.; SANTOS, A. S. Agricultores familiares e cientistas: diálogo de saberes sobre as variedades crioulas de milho no estado da Paraíba. Cienc. Cult., São Paulo, v.69, n.2, p.34-37, 2017. Disponível em: $<$ http://cienciaecultura.bvs.br/scielo.php?script=sci_arttext\&pid=S0009$67252017000200012 \& \operatorname{lng}=$ en\&nrm=iso $>$. Acessado em setembro de 2018. http://dx.doi.org/10.21800/2317-66602017000200012.

TRINDADE, C. C. Sementes crioulas e transgênicos: uma reflexão sobre sua relação com as comunidades tradicionais. XV Congresso Nacional do Conpedi - Manaus/AM - 15 a 18 de novembro de 2006. 


\section{SOBRE OS AUTORES}

\section{TÂNIA HALLEY OLIVEIRA PINTO}

Professora no curso de Licenciatura em Educação do Campo, área do conhecimento: Ciências da Natureza na Universidade Federal do Triângulo Mineiro, Mestre e Doutoranda pela Universidade Federal de Minas Gerais, na linha de Educação e Ciências. Docente à frente da disciplina de Genética e Evolução nas experiências mencionadas, integra o grupo de pesquisa Integração de Saberes na Formação de Professores de Ciências para o Campo.

\section{VERÔNICA KLEPKA}

Professora no curso de Licenciatura em Educação do Campo, área do conhecimento: Ciências da Natureza na Universidade Federal do Triângulo Mineiro, Doutora em Educação para a Ciência e a Matemática, pela Universidade Estadual de Maringá, atua no Programa de Pós Graduação em Educação em Ciências e Matemática (PPGECM- UFTM), na linha Cultura, construção do conhecimento e suas interfaces com a Educação em Ciências e Matemática e integra o grupo de pesquisa Integração de Saberes na Formação de Professores de Ciências para o Campo. Docente das disciplinas de Genética e Evolução e Botânica nas experiências mencionadas.

\section{MIKAELLA DE SOUSA}

Professora de Química da Rede Estadual de Minas Gerais e da Escola SESI de Uberaba, Mestra em Ensino de Ciências pela Universidade Federal do ABC (UFABC), pesquisadora integrante do grupo de pesquisa Integração de Saberes na Formação de Professores de Ciências para o Campo.

\section{RODRIGO DOS SANTOS CREPALDE}

Professor no curso de Licenciatura em Educação do Campo, área do conhecimento: Ciências da Natureza na Universidade Federal do Triângulo Mineiro. Doutor em Educação, pela Universidade Federal de Minas Gerais, atua no Programa de Pós Graduação em Educação em Ciências e Matemática (PPGECM- UFTM), na linha Cultura, construção do conhecimento e suas interfaces com a Educação em Ciências e Matemática, pesquisador integrante do grupo de pesquisa Integração de Saberes na Formação de Professores de Ciências para o Campo. 